\title{
The activity and properties of an acidic triacylglycerol lipase from adult and fetal rat lung
}

\author{
Bob Brooks * and Paul A. Weinhold ** \\ Veterans Administration Medical Center and Department of Biological Chemistry, University of Michigan, Ann Arbor, MI \\ (U.S.A.)
}

(Received May 28th, 1985)

Key words: Triacylglycerol lipase; Lung; Development; (Rat)

Triacylglycerol lipase with maximal activity at $\mathrm{pH} 5$ was present in adult and fetal lung. The activity was inhibited by serum concentrations used to measure lipoprotein lipase and by $0.5 \mathrm{M} \mathrm{NaCl}$. The activity in homogenates from fetal lung was about $40 \%$ of the activity in adult lung homogenates. The activity increased to $80 \%$ of the adult levels during the first $24-48 \mathrm{~h}$ following birth. Acidic triacylglycerol lipase was present in all subcellular fractions from adult lung. However, the major amount of activity appeared to be associated with lysosomes. Fetal lung contained significantly more activity in the cytosolic fraction compared to the adult. The reaction produced free fatty acids $(65 \%), 1,2(2,3)$-diacylglycerol $(22 \%)$ and 2-monoacylglycerol (12\%). Minimal amounts of 1,3-diacylglycerol and 1(3)-monoacylglycerol were formed. Diacylglycerol lipase and monoacylglycerol hydrolase activities at $\mathrm{pH} 5$ were independently determined and both were higher than the triacylglycerol lipase activity. The subcellular distribution of diacylglycerol lipase and monoacylglycerol hydrolase differed from that of triacylglycerol lipase. Overall, the results indicated that the lung has considerable intracellular lipase activity and therefore could readily hydrolyze intracellular triacylglycerol to free fatty acids. The reaction also produced significant amounts of 1,2-diacylglycerol which suggests that triacylglycerol could be a direct source of diacylglycerol for phospholipid synthesis.

\section{Introduction}

Phospholipid metabolism in the lung has been studied extensively. Special emphasis has been placed on the biosynthesis of phosphatidylcholine, particularly the dipalmitoyl species, because of its involvement as the major surface-active component of pulmonary surfactant $[1,2]$. The capacity for phospholipid synthesis in the lung requires a continuous supply of fatty acids. Numerous studies have shown that fatty acids can be supplied from the novo synthesis [3-7], from the uptake of

\footnotetext{
* Present address: Institute of Marine Resources, University of California, Davis, CA 95616, U.S.A.

** To whom correspondence should be addressed.
}

free fatty acid from blood $[4,5]$ and from the hydrolysis by lipoprotein lipase of triacylglycerol contained in chylomicrons and serum lipoprotein [8-12].

Since lung contains significant amounts of triacylglycerol $[13,14]$, the intracellular hydrolysis of triacylglycerol is another potential source of free fatty acid and perhaps diacylglycerol. Furthermore, a lipid-containing interstitial cell has been shown to be present in the walls of alveoli, particularly prevalent during the postnatal period of alveolar proliferation [15]. It has been suggested that this cell may be a source of precursors for the synthesis of phospholipids in type II cells which are often observed to be in contact with the lipidcontaining interstitial cell [14]. The mobilization of 
this triacylglycerol would require the action of an intracellular triacylglycerol lipase. Although cytochemical studies have demonstrated the association of esterase activity with the lipid aggregates of interstitial cells [16], the activity and properties of intracellular triacylglycerol lipase from lung has not been examined in any detail. Coleman and Haynes [17] recently reported that lung microsomes contained a $\mathrm{Mn}^{2+}$-stimulated triacylglycerol lipase but no detailed studies of this enzyme from lung were reported.

In this report we present the results of studies on the activity and properties of an acidic triacylglycerol lipase from adult and fetal rat lung.

\section{Experimental procedure}

\section{Materials}

Rats were obtained from the Holtzman Co. Tri $\left[9,10-{ }^{3} \mathrm{H}\right]$ oleoylglycerol $(100-150 \mathrm{Ci} / \mathrm{mmol})$ and $\left[1-{ }^{14} \mathrm{C}\right]$ oleic acid $(40-60 \mathrm{mCi} / \mathrm{mmol})$ were obtained from New England Nuclear. Di[1${ }^{14} \mathrm{C}$ ]oleoylglycerol $(118 \mathrm{mCi} / \mathrm{mmol})$ and mono[1${ }^{14} \mathrm{C}$ ]oleoylglycerol $(59 \mathrm{mCi} / \mathrm{mmol})$ were obtained from Rosechem Products. Chromatographic analysis of the di[ $\left[1{ }^{14} \mathrm{C}\right]$ oleoylglycerol indicated that it consisted of 75\% 1,3-dioleoylglycerol, 24\% 1,2-dioleoylglycerol. Therefore, dioleoylglycerol (85\% 1,3-, 15\% 1,2-; Sigma Chem. Co. D3380) was used as substrate carrier for the radioactive dioleoylglycerol. Monooleoylglycerol, 1,3-dioleoylglycerol and fatty acids were also from Sigma. Trioleoylglycerol was purchased from both Sigma and Serdary Research Laboratory. 2-Monooleoylglycerol was obtained from Serdary. Phosphatidic acid was obtained from Serdary and phosphatidylserine (porcine brain) was purchased from ICN. Other phospholipids were obtained from Sigma. Bovine serum albumin was purchased from Sigma and Miles Laboratories. Hemoglobin, cytochrome $c$, NADPH, $p$-nitrocateochol sulfate, and $\beta$ glycerophosphate were obtained from Sigma. All other chemicals were reagent grade.

\section{Preparation of homogenates}

The rats (female, Sprague-Dawley 140-180 g) were anesthetized by an intraperitoneal injection of $1 \mathrm{ml}$ of $10 \%$ chloral hydrate. The abdomen was opened and the inferior vena cava was cut. The chest was opened and the lung was perfused with isotonic saline through the pulmonary artery. Simultaneously, the lung was alternately inflated and deflated by connecting a mask to a respiration pump and placing the mask over the nose and mouth of the rat. The lung was then removed and placed in an ice-cold beaker. Subsequent operations were performed at $4^{\circ} \mathrm{C}$. The lung was weighed, cut into small pieces, and homogenized in a glass tissue grinder by two or three strokes of a motor-driven Teflon pestle in a sufficient volume of $0.25 \mathrm{M}$ sucrose/ $10 \mathrm{mM}$ Tris- $\mathrm{HCl}(\mathrm{pH} \mathrm{7.4)}$ to make a $10 \%(\mathrm{w} / \mathrm{v})$ homogenate. The mixture was passed through a No. 50 stainless steel screen in order to remove connective tissue and other debris.

Pregnant rats were killed by decapitation and the fetuses were removed and decapitated. The combined lungs from a litter were homogenized as described for adult lung.

\section{Preparation of subcellular fractions}

The homogenate was centrifuged at $600 \times g$ for $10 \mathrm{~min}$. The resulting pellet was rehomogenized in $2 \mathrm{ml}$ of homogenizing buffer and centrifuged again at $600 \times g$ for $10 \mathrm{~min}$. The supernatants were combined and centrifuged at $25000 \times g$ for 10 $\mathrm{min}$. The pellet was washed once by resuspension followed by centrifugation at $25000 \times g$ for 10 min. The supernatants were combined and centrifuged at $250000 \times \mathrm{g}$ for $60 \mathrm{~min}$ to give a microsomal pellet and a cytosol fraction. In some experiments a $10000 \times g$ fraction was used. This was obtained from the $600 \times g, 10$ min supernatant by centrifugation at $10000 \times \mathrm{g}$ for $10 \mathrm{~min}$.

\section{Preparation of trioleoylglycerol substrate}

A stock solution of $\left[{ }^{3} \mathrm{H}\right]$ trioleoylglycerol was prepared by dissolving $440 \mathrm{mg}$ of trioleoylglycerol and sufficient $\left[{ }^{3} \mathrm{H}\right]$ trioleoylglycerol in hexane to obtain a solution which contained $67 \mathrm{mM}$ (600-1000 dpm/nmol) trioleoylglycerol. The actual amount of trioleoylglycerol in the solution was quantified using the triacylglycerol assay system supplied by Sigma Chemical Company. The amount of radioactivity was determined in a liquid scintillation spectrometer. We assumed that the fatty acids in trioleoylglycerol contained equivalent radioactivity. The solution was stored under $\mathrm{N}_{2}$ at $-40^{\circ} \mathrm{C}$. 
For some experiments the trioleoylglycerol was purified before use. Four commercial $20 \times 20 \mathrm{~cm}$ thin-layer chromatography plates (Merck silica gel, $2 \mathrm{~mm}$ thick) were activated for $1 \mathrm{~h}$ at $110^{\circ} \mathrm{C}$. The labelled trioleoylglycerol was spotted on these plates in $18 \mathrm{~cm}$ bands and developed in hexane/ diethyl ether/acetic acid/ethanol (60:40:1:1, $\mathrm{v} / \mathrm{v})$. The triacylglycerol bands were scraped into 50-ml centrifuge tubes. The silica powder was extracted three times with $20 \mathrm{ml}$ of chloroform/ methanol $(2: 1, \mathrm{v} / \mathrm{v})$. The extracts were combined and solvent was evaporated under $\mathrm{N}_{2}$ to a small volume, and then filtered through glass wool. The purified trioleoylglycerol was dissolved in hexane and its radioactive purity was checked by TLC and found to be greater than $98 \%$ using the above solvent system. Purification did not affect enzyme activities but reduced the blank values.

The hexane was evaporated from an aliquot of the $\left[{ }^{3} \mathrm{H}\right]$ trioleoylglycerol solution and the substrate emulsion was prepared by adding sufficient buffer $(100 \mathrm{mM}$ acetate $(\mathrm{pH} 5.0)+0.26 \mathrm{mg} / \mathrm{ml}$ Triton $\mathrm{X}-100)$ to make a $3 \mathrm{mM}$ suspension of $\left[{ }^{3} \mathrm{H}\right]$ trioleoylglycerol. The mixture was homogenized for 5 min at $4^{\circ} \mathrm{C}$ using a Polytron. The opaque emulsion was stable for several hours but was generally used within $1-2 \mathrm{~h}$ after preparation.

\section{Triacylglycerol lipase assay}

The incubation mixture consisted of $0.1 \mathrm{ml}$ of the substrate emulsion in a total volume of $0.2 \mathrm{ml}$. Bovine serum albumin and EDTA were added so that the final concentrations were: $50 \mathrm{mM}$ acetate ( $\mathrm{pH} 5.0$ ), $0.13 \mathrm{mg} / \mathrm{ml}$ Triton X-100, $5 \mathrm{mg} / \mathrm{ml}$ bovine serum albumin, $1 \mathrm{mM}$ EDTA, and $1.5 \mathrm{mM}$ $\left[{ }^{3} \mathrm{H}\right]$ trioleoylglycerol. Enzyme preparation was added and the mixture was incubated at $37^{\circ} \mathrm{C}$. Fatty acid release was linear with time for $20 \mathrm{~min}$ and was proportional with protein up to at least 100 $\mu \mathrm{g}$.

The reaction was stopped by adding $50 \mu \mathrm{l}$ of borate-carbonate buffer ( $\mathrm{pH} 10.0$ ) which contained $100 \mathrm{nmol}$ of $\left[{ }^{14} \mathrm{C}\right]$ oleic acid $(3000 \mathrm{dpm})$. The fatty acids were extracted by the method of Belfrage and Vaughan [18]. The radioactivity was determined using a ${ }^{3} \mathrm{H} /{ }^{14} \mathrm{C}$ dual label program in the scintillation spectrometer. Total ${ }^{3} \mathrm{H}$-labelled fatty acids were calculated using the partition coefficient (range $0.58-0.72$ ) of the added $\left[{ }^{14} \mathrm{C}\right]$ oleic acid.
Dioleoylglycerol lipase and monoeleoylglycerol hydrolase assays

Since $\left[{ }^{14} \mathrm{C}\right]$ dioleoylglycerol and $\left[{ }^{14} \mathrm{C}\right]$ monooleoylglycerol were used, $\left[{ }^{14} \mathrm{C}\right]$ oleate could not be added as an internal standard for measuring the partition of fatty acids in the extraction process. Instead, a partition coefficient of 0.64 was used. This value was the average from 150 fatty acid partition experiments using the Belfrage and Vaughan system [18]. Other conditions were the same as described for triacylglycerol lipase except that the concentrations of dioleoylglycerol and monooleoylglycerol were $2.7 \mathrm{mM}$ and $0.69 \mathrm{mM}$, respectively. These amounts were determined to be optimal. Specific activities were $1830 \mathrm{dpm} / \mathrm{nmol}$ $\mathrm{l}^{14} \mathrm{C}$ ]dioleoylglycerol and $880 \mathrm{dpm} / \mathrm{nmol}$ $\left[{ }^{14} \mathrm{C}\right]$ monooleoylglycerol.

\section{Determination of lipoprotein lipase activity}

Lipoprotein lipase activity was measured essentially as described by Nilsson-Ehle and Shotz [19]. Trioleoylglycerol $(340 \mu \mathrm{mol})$ was mixed with 1.5 $\mu \mathrm{mol}$ tri $\left[1-^{14} \mathrm{C}\right]$ oleoylglycerol $\left(3 \cdot 10^{8} \mathrm{dpm}\right)$ and $2.15 \mathrm{mg}$ egg phosphatidylcholine. Glycerol $(6.25 \mathrm{~g})$ was added and the mixture was sonicated for 3 min at room temperature under $\mathrm{N}_{2}$. The assay substrate consisted of one part of the trioleoylglycerol-phosphatidylcholine-glycerol mixture, one part of fresh heat-treated rat serum $\left(60^{\circ} \mathrm{C}\right.$ for 10 min) and four parts of $50 \mathrm{mM}$ Tris (pH 8.3) - 3\% bovine serum alhumin. The final concentrations of ingredients in the assay were $0.07 \mathrm{M}$ Tris ( $\mathrm{pH} \mathrm{8.0)}$, $1 \%$ bovine serum albumin, $5 \mathrm{mM}$ trioleoylglycerol, $8.3 \%$ glycerol, $8.3 \%$ rat serum, and $0.036 \mathrm{mg} / \mathrm{ml}$ phosphatidylcholine in a final volume of $0.2 \mathrm{ml}$. Blanks were zero-time blanks in which the reaction was stopped with $3.25 \mathrm{ml}$ methanol/chloroform/ heptane $(141: 125: 100, \mathrm{v} / \mathrm{v})$ immediately after adding the enzyme. The fatty acids were isolated by solvent partition as described for the acidic triacylglycerol lipase procedure.

\section{Marker enzyme assays}

Succinate: cytochrome $c$ reductase was assayed as described by Sottocasa et al. [20]. NADPH : cytochrome $c$ reductase was measured as described by Williams and Kamin [21]. For the latter two enzymes the extinction coefficient of cytochrome $c$ 
was considered to be $21.0 \mathrm{mM}^{-1} \cdot \mathrm{cm}^{-1}$ at $550 \mathrm{~nm}$ [22].

Acid phosphatase was assayed as follows: 150 $\mu 1$ of $0.1 \mathrm{M}$ acetate $(\mathrm{pH} 5.0)$ were added to a test-tube. $50 \mu 1$ of $7.5 \mathrm{mg} / \mathrm{ml}$ Triton X-100, plus water and enzyme were added to make a total volume of $0.325 \mathrm{ml}$. The reaction was started by the addition of $50 \mu 1$ of $0.15 \mathrm{M} \beta$-glycerophosphate (except blanks) and incubated at $37^{\circ} \mathrm{C}$. The reactions were stopped by the addition of $0.25 \mathrm{ml}$ of ice-cold $10 \%$ trichloroacetic acid followed by placing the tubes on ice. $\beta$-Glycerophosphate was added to the blanks and the tubes were centrifuged at $2000 \mathrm{rpm}$ for $15 \mathrm{~min}$. Supernatant $(0.3 \mathrm{ml})$ was added to $0.7 \mathrm{ml}$ of color reagent ( 1 part $10 \%(\mathrm{w} / \mathrm{v})$ fresh ascorbic acid/ 6 parts $0.42 \%$ ammonium molybdata in $1.0 \mathrm{~N} \mathrm{H}_{\mathrm{S}} \mathrm{O}_{4}$ ). The tubes were heated at $100^{\circ} \mathrm{C}$ for $7 \mathrm{~min}$ and the absorbance was determined at $750 \mathrm{~nm}$.

\section{Determination of lipase products}

The reaction mixtures were extracted with $4 \mathrm{ml}$ of chloroform/methanol, $(2: 1, \mathrm{v} / \mathrm{v})$. Water $(0.8$ $\mathrm{ml}$ ) was added and the phases were separated by centrifugation. The chloroform extract was evaporated under $\mathrm{N}_{2}$ and the lipid redissolved in $1.0 \mathrm{ml}$ of chloroform. An aliquot was removed for determinations of total radioactivity. The remaining solution was evaporated to dryness, and the lipid was dissolved in $100 \mu 1$ of chloroform. Boric acid-impregnated plates were prepared by the emersion of $0.25 \mathrm{~mm}$ silica gel plates in $0.4 \mathrm{M}$ boric acid in methanol. Excess methanol was drained from the plate. The plates were air-dried thoroughly and activated at $110^{\circ} \mathrm{C}$ for $2 \mathrm{~h}$. One half of the sample $(50 \mu 1)$ was spotted on each of two plates. One plate was developed in chloroform/acetone/acetic acid/methanol (73:25: $0.5: 2, v / v)$ [25]. This system resolved 1(3)-monoacylglycerol and 2-monoacylglycerol. The second plate was developed in chloroform/acetone $(96: 4$, $\mathrm{v} / \mathrm{v}$ ). This system resolved triacylglycerol, 1,2-diacylglycerol, 1,3-diacylglycerol, fatty acids and monoacylglycerol [23].

The spots were visualized with $I_{2}$ vapor and scraped into test-tubes. Each sample was extracted three times with $2 \mathrm{ml}$ of chloroform/methanol/ acetic acid/water $(50: 39: 1: 10, \mathrm{v} / \mathrm{v})$. The extract was transferred to scintillation vials, dried under an air stream, and the amount of radioactivity was determined. The percent distribution of products was determined on both plates. These values were multiplied by the total radioactivity in order to calculate the nmol of each product. The percent distribution of 1(3)- and 2-monoacylglycerol on the first plate was used to calculate nmol of each species of monoacylglycerol produced by the reaction, based on the percent total monoacylglycerol determined from the second plate.

\section{Results}

Acid triacylglycerol lipase and lipoprotein lipase in homogenates

Lung homogenates contained triacylglycerol lipase with maximal activity at $\mathrm{pH} 5.0$ as well as lipoprotein lipase (Fig. 1). Fetal lung also contained lipase activity with a pH 5.0 maximum. The acidic lipase activity in adult lung was somewhat higher than lipoprotein lipase. The activity in fetal

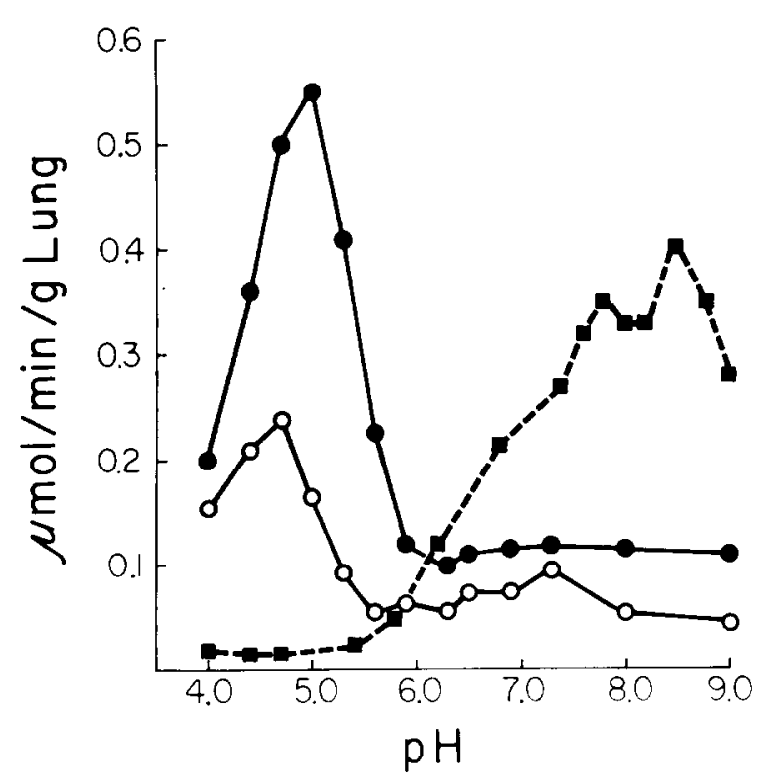

Fig. 1. The effect of $\mathrm{pH}$ on triacylglycerol lipase activity in adult and fetal lung homogenates. Lung homogenates from adult $(\bullet)$ and 20 day gestation fetal $(O)$ were assayed in 25 $\mathrm{mM}$ citrate $/ 50 \mathrm{mM}$ phosphate at $\mathrm{pH}$ below 8 . The activities at pH 8 and 9 were determined in $20 \mathrm{mM}$ acetate $/ 20 \mathrm{mM}$ sodium barbital. Triacylglycerol lipase activity in adult homogenates (a) was determined under conditions described in Methods for lipoprotein lipase. The buffer mixture was $70 \mathrm{mM}$ Tris $/ 70 \mathrm{mM}$ acetate $/ 70 \mathrm{mM}$ maleate. 
lung was considerably less than in adult lung homogenates. Under conditions for the measurement of lipoprotein lipase (in the presence of serum) no activity was present at $\mathrm{pH}$ 5.0. Similarly, under the conditions for acid lipase (the absence of serum) no activity was present at alkaline pH. Separate experiments showed that $8.3 \%$ serum caused a 10-fold increase in activity at $\mathrm{pH}$ 8.3 and $90 \%$ inhibition of activity at $\mathrm{pH} 5.0$. Serum at $2.5 \%$ inhibited the acidic lipase activity by $75 \%$. Acidic triacylglycerol lipase activity in fibroblasts also has been reported to be inhibited by serum [24].

The activity of acidic triacylglycerol lipase in homogenates was significantly lower in fetal lung than in adult (Fig. 2). The activity increased at birth and during the first $24-48 \mathrm{~h}$ after birth followed by a decline. Adult values were not reached during the development period investigated.

\section{Subcellular distribution of acidic triacylglycerol lipase}

Although acidic triacylglycerol lipase activity was present in all subcellular fractions, the distribution profile, when compared to marker enzymes, suggested that the major activity was associated with lysosomes (Fig. 3). In order to obtain further documentation, we separated the $25000 \times g$ pellet by centrifugation on a linear sucrose gradient. The

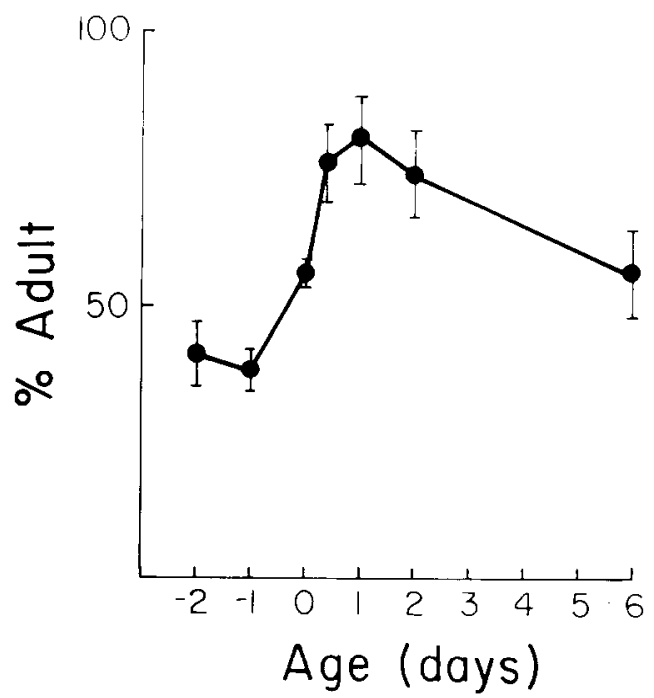

Fig. 2. Acidic triacylglycerol lipase activity during lung development. Each value is the mean \pm S.E. for three litters. The adult value was $0.68 \mu \mathrm{mol} / \mathrm{min}$ per $\mathrm{g}$ lung.

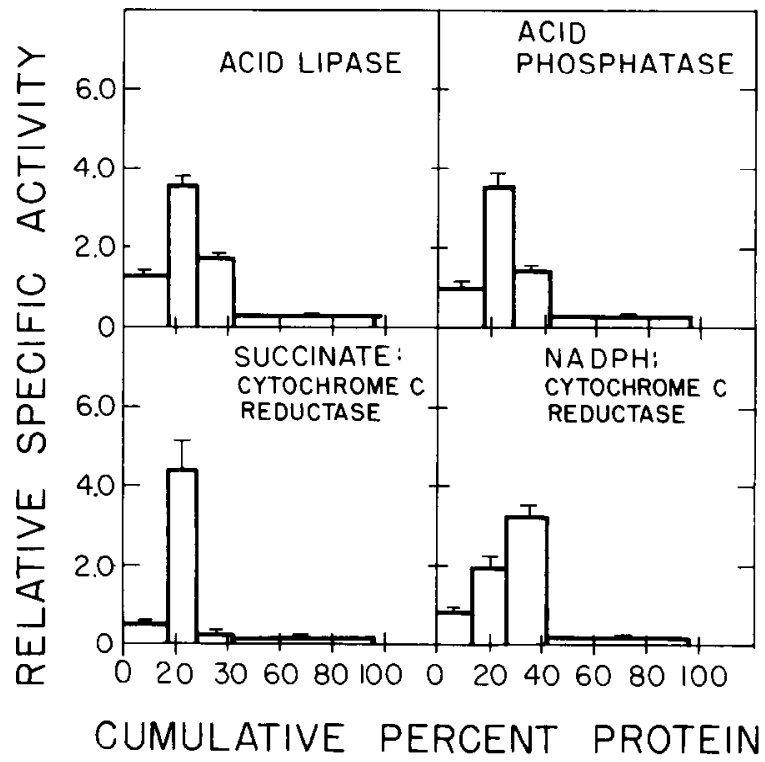

Fig. 3. The subcellular distribution of acidic triacylglycerol lipase compared to enzyme markers for mitochondria, microsomes and lysosomes. The relative specific activity $=$ specific activity in the fraction/specific activity in homogenate. Fractions in each panel, from left to right, are: $N=600 \times g$ for 10 min pellet; $\mathrm{M}=25000 \times g$ for $10 \mathrm{~min}$ pellet; $\mathrm{P}=250000 \times g$ for $60 \mathrm{~min}$ pellet and $\mathrm{S}=250000 \times \mathrm{g}$ for $60 \mathrm{~min}$ supernatant.

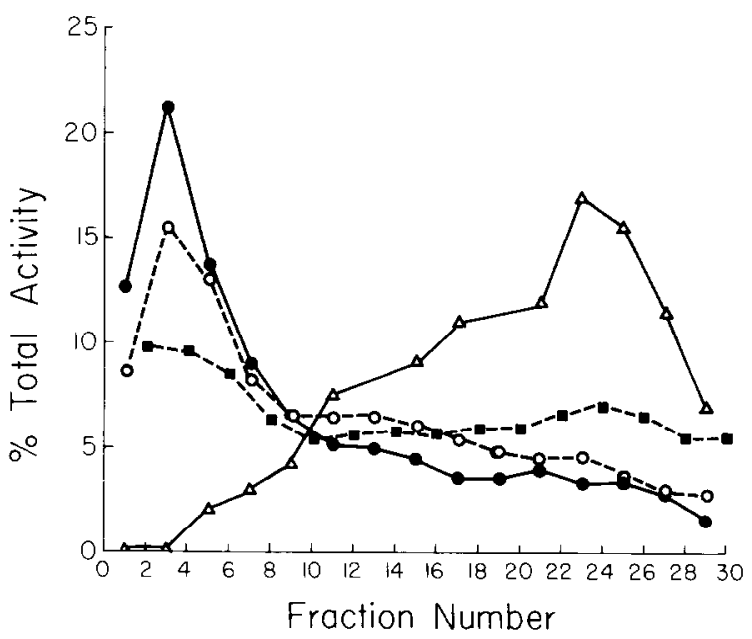

Fig. 4. The fractionation of the $25000 \times \mathrm{g}$ for $10 \mathrm{~min}$ pellet by density-gradient centrifugation. The activity profiles of acidic triacylglycerol lipase $(O)$, acid phosphatase $(\bullet)$, succinate cytochrome $c$ reductase $(\Delta)$ and protein $(\square)$ were determined. The gradient consisted of $6.0 \mathrm{ml}$ of $2.0 \mathrm{M}$ sucrose on the bottom with a linear gradient of $1.6 \mathrm{M}$ to $1.0 \mathrm{M}$ sucrose above the 2.0 $M$ sucrose. The sucrose was dissolved in $50 \mathrm{mM}$ Tris $/ 1 \mathrm{mM}$ EDTA (pH 7.0). Fractions of $1.0 \mathrm{ml}$ were collected. $77 \%$ recovery lipase, $96 \%$ phosphatase, $110 \%$ reductase. 
acidic lipase activity coincided with acid phosphatase activity and was well separated from the mitochondrial marker, succinate : cytochrome $c$ reductase (Fig. 4).

The distribution profile of acidic lipase in fetal lung was similar to that obtained with adult lung except that more activity was recovered in the $250000 \times g$ supernatant and less was found in the $25000 \times g$ pellet, relative to these fractions from the adult lung (Table I). The sum of the percentages found in these two fractions was nearly the same for both the adult and fetal lung, which may reflect differential strength of binding of acid lipase to the membrane in adult and fetal lung or a different subcellular location in the two tissues. The distribution of acid phosphatase between adult and fetal preparations was similar.

The $\mathrm{pH}$-activity relationships for triacylglycerol lipase activity in the $10000 \times g$ particulate and in the microsomal fraction were the same as obtained for the homogenate (data not shown). The activity in the $10000 \times g$ particulate and in the microsomes was inhibited by $\mathrm{NaCl}(28 \%$ at $0.1 \mathrm{M} ; 77 \%$ at $0.5 \mathrm{M}$ for adult and $19 \%$ at $0.1 \mathrm{M} ; 79 \%$ at $0.5 \mathrm{M}$ for fetal).

\section{TABLE I}

SUBCELLULAR DISTRIBUTION OF ACIDIC TRIACYLGLYCEROL LIPASE AND ACID PHOSPHATASE FROM ADULT AND FETAL LUNG

The results are expressed as percent of activity in the homogenate. The values represent means $\pm S$.E., with $n$ equal to the number of animals for the adult and the number of litters for the fetal. * and ** indicate statistically significant differences with $P<0.001$.

\begin{tabular}{lcccc}
\hline Fraction & \multicolumn{2}{l}{ Acid lipase } & \multicolumn{2}{l}{ Acid phosphatase } \\
\cline { 2 - 3 } \cline { 5 - 6 } & adult & fetal & adult & fetal \\
& $(n=6)$ & $(n=3)$ & $(n=6)$ & $(n=3)$ \\
\hline $600 \times g$, & 22.0 & 24.2 & 15.7 & 13.1 \\
10 min pellet & \pm 2.7 & \pm 1.6 & \pm 0.6 & \pm 3.3 \\
$25000 \times g$, & $41.0^{*}$ & $18.7 *$ & 39.8 & 46.8 \\
10 min pellet & \pm 2.1 & \pm 1.3 & \pm 3.8 & \pm 6.2 \\
$250000 \times g$. & 23.8 & 20.1 & 18.6 & 21.7 \\
60 min pellet & \pm 1.2 & \pm 1.0 & \pm 1.0 & \pm 2.4 \\
$250000 \times g, 60$ min & $14.1 * *$ & $38.7 * *$ & 11.4 & 14.2 \\
supernatant & \pm 2.0 & \pm 4.4 & \pm 2.7 & \pm 3.9 \\
Recovery\% & 101.1 & 101.6 & 85.5 & 95.8 \\
\hline
\end{tabular}

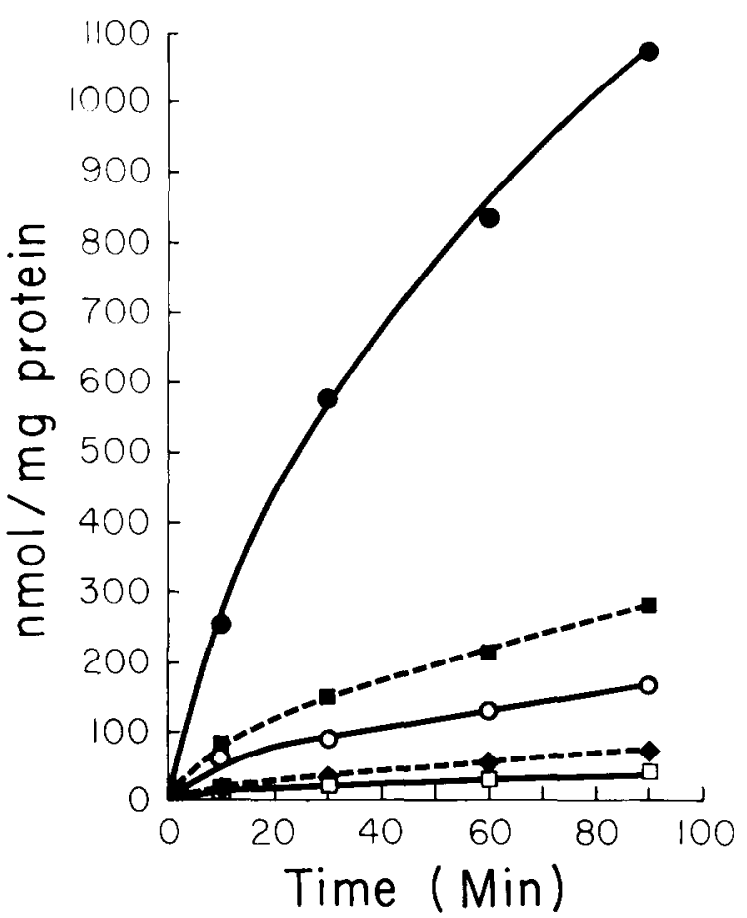

Fig. 5. Products formed from the acidic triacylglycerol lipase reaction in $10000 \times g$ for $10 \mathrm{~min}$ pellet from adult lung. $\bullet$, fatty acids; $\mathbf{\square}, 1,2(2,3)$-dioleoylglycerol; $O$, 2-monooleoylglycerol; $\bullet$, 1(3)-monooleoylglycerol; $L, 1,3$-dioleoylglycerol.

\section{Determination of reaction products}

The reaction produced free fatty acids, 1,2(2,3)-diacylglycerol and 2-monoacylglycerol (Fig. 5). The relative distribution of products remained the same at all time points (65-69\% fatty acids; $15-22 \%$ diacylglycerol and 9-13\% monoacylglycerol). The results in Fig. 5 were obtained with the $10000 \times g$ pellet and were similar to results obtained using the adult homogenate. Only minimal amounts of 1,3-diacylglycerol and 1(3)monoacylglycerol were found. Similar distribution of products was obtained with lung homognates from 20- and 21-day fetal and newborn animals.

\section{Effect of phospholipids and fatty acids}

Phosphatidylinositol, phosphatidylserine, phosphatidylglycerol and phosphatidic acid inhibited acid triacylglycerol lipase activity in the $10000 \times g$ pellet up to $70 \%$ at concentrations above 0.05 $\mathrm{mg} / \mathrm{ml}$. Below $0.05 \mathrm{mg} / \mathrm{ml}$, phosphatidylglycerol and phosphatidylinositol stimulated the enzyme activity slightly. Stimulation of liver acid lipase by 
acidic phospholipids has been reported [25,26], but to a much greater extent than we observed with the lung enzyme.

Phosphatidylethanolamine, phosphatidylcholine, dipalmitoylphosphatidylcholine and cardiolipin had no effect. Fatty acids $(0.2 \mathrm{mM})$ inhibited the activity of lung acid triacylglycerol lipase by $30 \%$. This inhibition did not appear to depend on either fatty acid chain length or degree of unsaturation, since the same amount of inhibition was obtained with palmitate, oleate, stearate, palmitoleate and linoleate.

\section{Diacylglycerol lipase and monoacylglycerol hydro- lase activities}

The products identified from the hydrolysis of trioleoylglycerol may have been produced by triacylglycerol lipase alone or by a combination of separate triacylglycerol lipase, diacylglycerol lipase and monoacylglycerol hydrolase activities. In order to obtain some insight into the possible involvement of hydrolytic activities other than triacylglycerol lipase, we examined the activities of diacylglycerol lipase and monoacylglycerol hydrolase at $\mathrm{pH}$ 5.0. The substrates were prepared with Triton X-100 by the same procedure as used for trioleoylglycerol. The reaction mixtures were the same as used for trioleoylglycerol lipase except that $\left[{ }^{14} \mathrm{C}\right]$ dioleoylglycerol or $\left[{ }^{14} \mathrm{C}\right]$ monoleoylglycerol were substituted for the trioleoylglycerol. The activities of diacylglycerol lipase and monoacylglycerol hydrolase were higher than the tri- acylglycerol lipase from adult lung and fetal lung (Table II). Furthermore, there was considerably more diacylglycerol lipase and monocylglycerol hydrolase activity than triacylglycerol lipase in the cytosol fraction. However, the diacylglycerol lipase and triacylglycerol lipase activities in the particulate fraction had the same relative distribution in the different particulate fractions for both the adult and retal. Furthermore, cytosolic diacylglycerol lipase activity increased from 26 $\mu \mathrm{mol} / \mathrm{min}$ per $\mathrm{g}$ lung in fetal lung to $495 \mu \mathrm{mol} /$ min per $g$ lung in adult lung, whereas the cytosolic triacylglycerol activity increased from 15 in fetal lung to $66 \mu \mathrm{mol} / \mathrm{min}$ per $\mathrm{g}$ lung in adult lung. The distribution of monoacylglycerol hydrolase activity does not coincide with the triacylglycerol lipase activities. Although these results suggest that separate enzymes may exist for these reactions, the evidence is indirect and must be substantiated by further enzyme isolation and characterization.

\section{Discussion}

Our results demonstrated that both adult and fetal lung contained triacylglycerol lipase with a $\mathrm{pH} 5$ optimum. This activity was strongly inhibited by serum and therefore was not observed under conditions used to measure lipoprotein lipase. While the activity was present in all of the particulate fractions, evidence was obtained which indicated that activity was primarily associated with lysosomes. In this regard the lung is similar to

\section{TABLE II}

\section{SUBCELLULAR DISTRIBUTION OF LIPASE ACTIVITIES IN ADULT AND FETAL LUNG (20 DAY GESTATION)}

The results are presented as relative specific activity which is defined as (specific activity of fraction) $/($ specific activity of $600 \times g$ supernatant). Specific activities of the $600 \times \mathrm{g}$ supernatant were the following. Using trioleoylglycerol: adult, $10.15 \mathrm{nmol}$ fatty acid/min per mg protein; fetal, $6.09 \mathrm{nmol} / \mathrm{min}$ per $\mathrm{mg}$. Using dioleoylglycerol: adult, $34.81 \mathrm{nmol} / \mathrm{min} \mathrm{per} \mathrm{mg;} \mathrm{fetal,} 12.46 \mathrm{nmol} / \mathrm{min}$ per $\mathrm{mg}$. Using monooleoylglycerol: adult, $16.65 \mathrm{nmol} / \mathrm{min}$ per $\mathrm{mg}$; fetal, $11.03 \mathrm{nmol} / \mathrm{min}$ per $\mathrm{mg}$.

\begin{tabular}{|c|c|c|c|c|c|c|}
\hline \multirow[t]{2}{*}{ Fraction } & \multicolumn{2}{|c|}{ Triacylglycerol lipase } & \multicolumn{2}{|c|}{ Diacylglycerol lipase } & \multicolumn{2}{|c|}{ Monoacylglycerol hydrolase } \\
\hline & adult & fetal & adult & fetal & adult & fetal \\
\hline $10000 \times g$ pellet & 2.04 & 3.20 & 1.80 & 3.35 & 0.95 & 1.34 \\
\hline $25000 \times g$ pellet & 1.41 & 1.92 & 1.19 & 2.45 & 0.83 & 0.95 \\
\hline $250000 \times g$ pellet & 1.06 & 0.94 & 0.95 & 0.96 & 1.08 & 0.85 \\
\hline $250000 \times g$ supernatant & 0.19 & 0.10 & 0.43 & 0.08 & 0.74 & 0.46 \\
\hline $\begin{array}{l}\text { Total activity } \\
\text { recovered (\%) }\end{array}$ & 70.7 & 71.4 & 78.5 & 75.5 & 85.2 & 68.9 \\
\hline
\end{tabular}


other tissues which have been reported to contain acidic triacylglycerol lipase in lysosomes [24,27-30]. Lysosomal triacylglycerol lipase in the various tissues is believed to hydrolyze triacylglycerol and cholesterol esters that enter via receptor-mediated uptake of serum lipoproteins [31]. Although the lung has been shown to hydrolyze lipoproteins through lipoprotein lipase action [9-11], the involvement of receptor-mediated uptake of serum lipoproteins in lipid metabolism in the lung has not been considered in detail. Hass and Longmore [32] used perfused lung preparations to demonstrate the existence of LDL and HDL receptors in adult rat lung.

DeBeer et al. [33] suggested that lysosomal triacylglycerol lipase may function to hydrolyze intracellular stores of triacylglycerol. This suggestion was based upon data which indicated that lysosomal triacylglycerol lipase was the only intracellular triacylglycerol lipase. However, other studies have demonstrated the presence of a microsomal triacylglycerol lipase in liver [17] and in brain [34]. Our results showing acidic triacylglycerol lipase activity in the microsomes do not rule out the possibility of a minor species of microsomal acid lipase. However, the similar distribution of acid triacylglycerol lipase activity with the activities of the lysosomal marker enzyme acid phosphatase suggests that the majority of pulmonary acid triacylglycerol lipase is located in the lysosomes; our results do not exclude the possibility that lamellar bodies may contain acid triacylglycerol lipase. Hook and Gilmore [35] have reported that variety of acidic hydrolases are present in lamillar bodies and that the hydrolase complement of lamillar bodies are similar to that of lysosomes.

The similar distribution of triacylglycerol lipase and diacylglycerol lipase activities in particulate fractions is consistent with the possibility that these activities in the particulate fraction are associated with the same enzyme. However, the presence of relatively high diacylglycerol lipase activity in the cytosolic fractions may indicate that a separate diacylglycerol lipase may exist in the adult, but not in fetal lung. The latter point is shown by the differences in distribution of activity between the soluble and particulate fractions from adult and fetal preparations. Furthermore, the comparative distribution of monoacylglycerol hydrolase in- dicates that this is separate from the triacylglycerol lipase. This is consistent with results from other tissues in which monoacylglycerol hydrolase activity was found not to be associated with triacylglycerol lipase $[36,37]$.

Rat lung acidic triacylglycerol lipase apparently displays positional specificity. As with acidic triacylglycerol lipase from other tissues [34,36,38], lipoprotein lipase [39] and pancreatic lipase [40], pulmonary acidic triacylglycerol lipase preferentially hydrolyzes the primary acyl bonds of triacylglycerol. It is therefore possible that triacylglycerol lipase may hydrolyze the fatty acyl group from the 3-position to produce 1,2-diacylglycerol which in turn could be used directly in the synthesis of phospholipids.

The developmental rise in acidic triacylglycerol lipase activity coincides with a rise in the amount of diacylglycerol in the lung [13]. Moreover, the rapid increase in activity following birth parallels the rise in triacylglycerol concentration in serum [41] and the increase in lipoprotein lipase activity [12]. These coincident increases would enable the lung in newborns to rapidly produce fatty acids from serum triacylglycerol and from intracellular triacylglycerol.

The interstitial cells in the neonatal lung contain numerous lipid aggregates [42]. The lipid aggregates are particularly prominent in a specific cell type, the lipofibroblasts, which has numerous lipid aggregates as its primary ultrastructural feature $[14,15]$. These lipid aggregates disappear during the postnatal period from birth to weaning. The acidic triacylglycerol lipase could be involved in the mobilization of these lipids, which have been shown to be mainly triacylglycerol [15]. However, the relative high activity of triacylglycerol lipase in adult lung argues against a specific localization of the triacylglycerol lipase in the lipofibroblast, since these cells are practically absent in adult lung [15].

\section{Acknowledgements}

This work was supported by the Veterans Administration and by a grant from the National Institute of Child Health and Human Development. 


\section{References}

1 Van Golde, L.M.G. (1976) Am. Rev. Respir. Dis. 114. 977-1000

2 Akino, T. and Ohno, K. (1981) CRC Crit. Rev. Toxicol. 9. 201-274

3 Buechler, K.F. and Rhoades, R.A. (1980) Biochim. Biophys. Acta $619,186-196$

4 Wang, M.C. and Meng, H.C. (1974) Lipids 9, 63-67

5 Jobe, A. (1979) Biochim. Biophys. Acta 572, 404-412

6 Maniscalco, W.M., Finkelstein. J.N. and Pankhurst, A.B. (1982) Biochim. Biophys. Acta 711, 49-58

7 Schiller, H. and Bensch, K. (1971) J. Lipid Res. 12, 248254

8 Scow, R.O., Hamosh, M., Blanchette-Mackie, E.J. and Evans, A.J. (1972) Lipids 7, 497-505

9 Hamosh, M., Naghshineh, S., Gal, S.G. and Hamosh, P. (1977) Am. Rev. Respir. Dis. 115. 335-342

10 Hamosh, M. and Hamosh, P. (1975) Biochim. Biophys. Acta 380, 132-140

11 Hamosh, M., Yeager, H., Shechter, Y. and Hamosh, P. (1976) Biochim. Biophys. Acta 431, 519-525

12 Cryer, A. and Jones, H.M. (1978) Biochem. J. 174, 447-451

13 Ishidate. K. and Weinhold, P.A. (1981) Biochim. Biophys. Acta 664, 133-147

14 Tordet, C., Marin, L. and Dameron, F. (1981) Experientia 37, 333-334

15 Maksvytis, H.J., Vaccaro, C. and Brody, J.S. (1981) Lab. Invest. 45, 248-259

16 O'Hare, K.H., Reiss, O.K. and Vatter, A.E. (1971) J. Histochem. Cytochem. 19. 97-105

17 Coleman, R.A. and Haynes, E.B. (1983) Biochim. Biophys. Acta $751,230-240$

18 Belfrage, P. and Vaughan, M. (1967) J. Lipid Res. 10, 341-344

19 Nilsson-Ehle, P. and Shotz, M.C. (1976) J. Lipid Res. 17, 536-541

20 Sottocasa, G.L., Kuylenstierna, B., Ernsten, L. and Bergstrand, A. (1967) J. Cell Biol. 32, 415-438.

21 Williams, C.H. and Kamin, H. (1962) J. Biol. Chem. 237, $587-595$
22 Massey, V. (1959) Biochim. Biophys. Acta 34. 255-256

23 Thomas, A.E., Scharoun. J.E. and Ralston. H. (1965) J. Am. Oil Chem. Soc. 42, 789-792

24 Oram, J.F., Shafrir, E. and Bierman. E.L. (1980) Biochim. Biophys. Acta 619, 214-227

25 Teng, M.H. and Kaplan. A. (1974) J. Biol. Chem. 249. 1064- 1070

26 Karija, M. and Kaplan, A. (1973) J. Lipid Res. 14, 243-249

27 Mahadevan, S. and Tappel, A.L. (1968)-J. Biol. Chem. 243, 2849-2854

28 Burton, B.K. and Mueller. H.W. (1980) Biochim. Biophys. Acta $618,449-460$

29 Severson. D.L., Sloan. S.K. and Kryski. A. (1981) Biochem. Biophys. Res. Commun. 100, 247-253

30 Rindler-Ludwig, R., Patsch, W., Sailer, S. and Braunsteiner, H. (1977) Biochim. Biophys. Acta 488, 294-304

31 Brown, M.S. and Goldstein. J.L. (1976) Science 191, 150-154

32 Hass, M.A. and Longmore. W.J. (1980) Lipids 15, 40I-406

33 DeBeer, L.J., Thomas, J., DeSchepper, P.J. and Mannaerts. G.P. (1979) J. Biol. Chem. 254, 8841-8846

34 Cabot, M.C. and Gatt, S. (1978) Biochim. Biophys. Acta $530,508-512$

35 Hook. G.E.R. and Gilmore. L.B. (1982) J. Biol. Chem. 257. 9211-9220

36 Warner, T.G., Dambach, L.M., Shin, J.H. and O'Brien. J.S. (1981) J. Biol. Chem. 256, 2952-2957

37 Berglund, L.. Khoo, J.C., Jensen, D. and Steinberg, D. (1980) J. Biol. Chem. 255, 5420-5428

38 Hayase, K. and Tappel, A.L. (1970) J. Biol. Chem. 245, $169-175$

39 Nilsson-Ehle, P., Egelrud, T.. Belfrage, P.. Olivecrona, T. and Borgstrom, B. (1973) J. Biol. Chem. 248, 6734-6737

40 Mattson, F.H. and Volpenhein. R.A. (1968) J. Lipid Res. 9. $79-84$

41 Cryer, A. and Jones, H.M. (1978) Biochem. J. 172, 319-325

42 O'Hare, K.H. and Scheredan, M.N. (1970) Am. J. Anat. $127,181-192$ 